JOURNAL OF SECURITY AND SUSTAINABILITY ISSUES

ISSN 2029-7017 print/ISSN 2029-7025 online

2018 December Volume 8 Number 2

https://doi.org/10.9770/jssi.2018.8.2(4)

Scopus

\title{
THE IMPORTANCE OF SUSTAINING SECURE AMBIENCE FOR CADETS OF THE MILITARY ACADEMY OF LITHUANIA VIA BALANCING EMOTIONS AND PERCEPTION IN ATTAINING ACCELERATED SECOND LANGUAGE LEARNING AND ACQUISITION
}

\author{
${ }^{1}$ Dileta Jatautaite, ${ }^{2}$ Jelena Kazimianec \\ General Jonas Žemaitis Military Academy of Lithuania, Šilo Str. 5A, LT-10322 Vilnius, Lithuania \\ E-mails:'1dileta.jatautaite@mil.lt, ${ }^{2}$ kazimelen@gmail.com
}

Received 11 January 2018; accepted 25 May 2018; published 30 December 2018

\begin{abstract}
The article scrutinizes the importance of sustaining secure ambience for cadets of the Military Academy of Lithuania (MAL) via balancing emotions and perception in attaining accelerated second language learning and acquisition. This Confluent approach to the second language learning and acquisition was constructed by the teachers of MAL to facilitate and accelerate the second language learning and acquisition of the learners via sustaining secure ambience through balancing their emotions and cognitive features necessary for gaining best effect of second learning and acquisition. Consequently, the already constructed Confluent (holistic, emotionally and cognitively balanced) second foreign language learning and acquisition approach, will significantly sustain secure ambience for the learners which will lead to accelerated foreign language learning and acquisition. In terms of verification of this hypothesis, the research was carried out with cadets of the Military Academy of Lithuania. Experimentally achieved results are presented in the article.
\end{abstract}

Methods: group work, free conversation, monologue, free discussion, free expression, interpersonal sharing, concert, dialogue, debating; here and now teaching, student output as class content for language practice, interpersonal sharing and self-awareness.

Keywords: Gestalt theory, Confluent language learning and acquisition approach, cognitive ability, affective capacity, design, collateral learning, ambience.

Reference to this paper should be made as follows: Jatautaite, D.; Kazimienec, J. 2018. The Importance of Sustaining Secure Ambience for Cadets of the Military Academy of Lithuania Via Balancing Emotions and Perception in Attaining Accelerated Second Language Learning and Acquisition, Sustainability Issues, Journal of Security and Sustainability Issues 8(2): 161-170.

https://doi.org/10.9770/jssi.2018.8.2(4)

JEL Codes: I2, I23, I29

\section{Introduction}

There has always been a considerable interest in accelerating foreign language learning and acquisition but nothing can be so far compared with the need of fast second language learning, especially, for the military forces. There has always been a considerable interest in accelerating foreign language learning and acquisition but nothing can be so far compared with the need of fast second language learning, especially, for the military. Foreign language learning and acquisition diverse theories and other forms of education and training were correspondingly considered by different scientists in different times (Dewey 1938; Brown 1971; Lozanov 1978; Le Doux 1996; Thompson 2011; Radović-Marković 2011; Mačiulis; Tvaronavičienè 2013; Dzemyda et al. 2015; Dubauskas 2016; Hurbišová, Davidová 2016; etc.; Černevičiūtė, Strazdas 2018; Saleem et al. 2018; Lincaru et al. 2018; Labanauskis et al. 2018).

Knowledge of a foreign language, while being a significant instrument of communication, must be viewed as an enabler sustaining and guaranteeing safety and security of Lithuania and NATO allies. Here in, Mark 
Thompson (2011) in his article "The Pentagon's Foreign-Language Frustrations" marks that "learning the language will not only help one learn about that culture but be able to operate more effectively once immersed in it. Improving our language skills may lead to more effective and efficient techniques for building the capacity of our current and future partners and reduce the need for deployments of robust US forces". Leon Panetta (2011) in the same article stated that the language and cultural training is a key to U.S. global economic and security interests and that "languages are the key to understanding that world. If we are going to advance stability in some of the countries we are fighting in today, we have to be able to understand what motivates those countries, what motivates their people, and to understand their culture, beliefs, faiths, ideologies, hatreds and loves. Strong language ability is necessary to do that". So that to achieve these goals, none of the traditional substitutes for personal proficiency (machine translation, contract interpreters, etc.) can achieve what is needed for a leading world power in military, diplomacy, intelligence, and security. Therefore, it means that a fast and accelerated language learning and acquisition and are essential for a successful career oriented contemporary NATO officer. And this is a new track to his/her success which enforces him to know as many as possible foreign languages, which require critical-thinking skills and a sense of international-mindedness from him/her. At the moment the global world is tension-charged, fast-paced and full of demands and complexities and this way of living has become a norm for an officer in today's challenging times. It is quite obvious that Lithuanian officers as well as civilians working for the MAL or National Defence System of Lithuania are also forced to study foreign languages almost all their life in terms of European Union's Lifelong Learning Programme (Smith 2014). Lifelong Learning Programme is essential if anyone wants to lead shifts with challenges of the global world and sustain his/her or the county's security and stability.

Thus, it is also salient to organize the methodology of the second foreign language learning and acquisition for MAL cadets, who are the future of the Lithuanian military leaders, by optimizing the learner's cognitive, and physical properties at a maximum degree and leading to successful and effective result via sustaining his/her secure ambience.

The problem of the research is how to attain accelerated language learning and acquisition of a learner via balancing emotions and perception on the basis of Confluent second language learning and acquisition approach leading to sustaining secure ambience for cadets of the Military Academy of Lithuania.

The purpose of the research is to explore the effectiveness of Confluent approach on accelerating language learning and acquisition via sustaining secure ambience for cadets of the Military Academy of Lithuania by balancing emotions and perception.

The object of the research is acceleration of the second foreign language learning and acquisition via sustaining secure ambience for cadets of the Military Academy of Lithuania through balancing emotions and perception on the basis of Confluent language learning and acquisition approach.

The methodology of the article is based on Williams and Burden's (1997) formulated Confluent approach who designed it on the Frederick "Fritz" Perls, L. Perls and P. Goodman's Gestalt psychotherapy foundation. Creative interchange is encouraged by Gestalt therapy when those involved in the learning process are productively willing to experiment; as a consequence, the chances for optimal and effective results of second language learning and acquisition are much higher with Gestalt techniques which indicate the importance of transferring implicit knowledge of the learner to the narrative explicit one. Thus means that for Gestalt implicit knowledge is most significant in forming second language learning and acquisition. Therefore, based on Gestalt theory Confluent language learning and acquisition approach was adapted, designed and constructed by teachers of the foreign language of the MAL. Moreover, this approach likewise involved the Humanism and its holistic attitude towards a human being when all senses and perception forces are kept all-inclusive balanced. Additionally, Confluent approach was considered by the researchers as holistic, aiming to activate and engage all of the learner's emotional and intellectual senses, endogenic and exogenic forces of a human being (Misch, Peloquin 2005). What is more, this approach is rooted in Dewey's (1938) notion of collateral learning as a "philosophy and a process of reaching and learning in which the affective domain and the cognitive 
domain flow together, like two streams merging into one river" (Brown 1971). The researchers considered Holistic methodology indispensable and pivoting slant in sustaining secure ambience for the learner learning the second foreign language once his/her body, mind, emotion and spirit of a human being are balanced and work together. Furthermore, Krashen's (1983) "affective filter" with Worde's (1998) language anxiety theories were scrutinized and applied in the research too. In addition, Lozanov's Suggestopedia method of a foreign language learning and acquisition on the foundation of positively stimulated emotions, feelings and cogitation, perception of an individual was reflected and implemented into the research whilst constructing the Confluent approach of the research.

\section{The effect of emotion and cognition blending in accelerating second language learning and acquisition}

Positive or negative emotional experiences externalize through learning and leave strong traces in the brain of the learner when memories are formed in a variety of systems that can possibly be separated into two capacious groups: supporting conscious memory (i.e. explicit memory) and storing information unconsciously (i.e. implicit memory). Memories about emotional situations are often stored in both kinds of systems (Figure 1) accordingly forming the impact of emotion on cognitive processes. Subsequently, it means that positive or negative emotions significantly influence the learner's explicit or implicit memory development through intensive language learning. Under these conditions, storing and recalling processes of the memory are getting limited in unsecure and uncomfortable ambience; as a result of such conditions, limitation of accelerated learning and acquisition happens; vice versa when positive and secure ambience is organized in the learning environment, implicit memory retrieval boosts by triggering accelerated language learning and acquisition. Therefore, Confluent language learning and acquisition approach is constructed on harmonizing holistic attitude to language learning of the learner when Creative interchange is encouraged by Gestalt therapy when those involved in the learning process are productively and willing experiment; as a consequence, the chances for optimal and effective results are much higher with Gestalt techniques for the implicit knowledge of the learner is transferred to the narrative explicit knowledge.

This process is best revealed by Joseph E. LeDoux (2007) who shows how Memories about emotional situations are stored in both kinds of systems (see Figure 1).

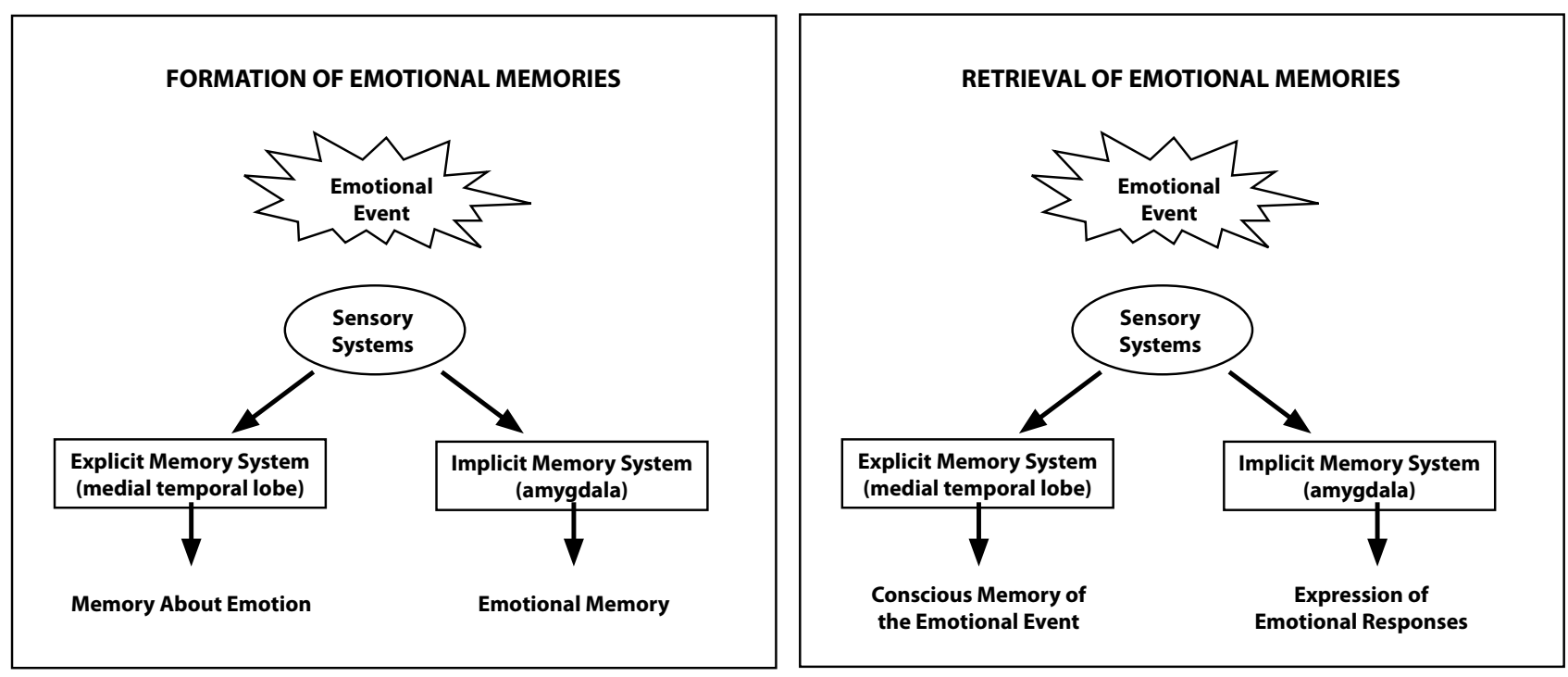

Figure 1: Right: Emotional Memories vs. Memories about Emotions. Left: Formation of emotional memories.

Source: based on Joseph E. LeDoux (2007)

In accordance to J. E. LeDoux (2007) Figure 1, emotional events are processed in sensory systems and then transmitted to the medial temporal lobe for the formation of an explicit memory around the emotional situation and to the amygdala for the formation of an emotional memory. When a signal from the memory occurs, it gets 
processed by the sensory system leading to the recall of an explicit memory around the emotional event in the medial temporallobe leading to the expression of emotional responses when recalled in the amygdala.

A. M. Isen (1990) asserts that "the material in mind is organized and accessible in terms of its positive affect tone, and that people spontaneously use positive affect as a way to organize their thoughts ....and common positive feelings are fundamentally involved in cognitive organization and processing". In the interim, Jensen (1998) suggests that emotions not only help us remember things that are most emotionally laden, but that emotions "give us a more activated and chemically stimulated brain: the more intense the amygdala arousal, the stronger the imprint". He also quotes Squire to support the view that "emotions are so important that they have their own memory "pathways" and "good learning does not avoid emotions, it embraces them".

Schumann (1994) comments that "brain stem, limbic and fronto-limbic areas, which comprise the stimulus appraisal system, emotionally modulate cognition such that, in the brain, emotion and cognition are distinguishable but inseparable". Therefore, extensive research on the physiological relationship between emotion and cognition has been conducted by Damasio (1994). According to him, the brain releases "chemical messages" which have a major impact on the efficiency of the cognitive process. This concept is applied to second language acquisition by Schumann (1990). Schumann explains that a gland in the brain, called the amygdala, evaluates emotional stimuli and relays "chemical messages" to other emotion centers of the brain. Once these emotion centers are activated, they may influence what is perceived and learned by an individual, contributing to accelerated second language learning and acquisition. Thus positive emotion, by triggering a chemical response in the amygdala, creates a pathway for successful language acquisition.

Worde (1998) carried a research which proved that some learners, in the negatively organized learning ambience, can obtain disturbing experience. According to him (Worde 1998), one third to one half of students examined reported experiencing debilitating levels of language anxiety. He also acknowledged that too much anxiety can lead to a debilitating effect, which may lead to work avoidance or inefficient performance. Moreover, anxiety can interfere in all language acquisition stages: input, process, and output and become, according to Krashen's (1983) postulate "affective filter" which acts before the Language Acquisition Device and impedes the learner's desire to seek input if the learner is not motivated enough. Besides, Krashen's (1983) "affective filter" prevents certain information from entering a learner's cognitive processing system in the negative and insecure ambience (Sellers 2000).

What is more, anxiety can influence both speed and accuracy of learning. Anxiety arousal can also impact on the quality of communication output as the retrieval of information can be interrupted by the "freezing-up" or "knocking - out" moments that students encounter when they get anxious or nervous. Moreover, it might happen that language learning experience, under some circumstances, can imperil a traumatic experience. This kind of unpleasant involvement can deeply disturb one's self-esteem or self-confidence as a learner.

\section{Methodological constructing of Confluent approach in accelerated second language learning and acquisition}

Being aware of how memories about emotional situations are stored and processed, it was important on this basis to reveal Gestalt therapy which was founded by Frederick "Fritz" Perls and colleagues Laura Perls and Paul Goodman and is the foundation of Confluent approach.

Gestalt therapy began as a revision of psychoanalysis (Perls 1992) and quickly developed as a wholly independent, integrated system (Perls et al. 1951). The therapy was based on is experiential and humanistic approach and dealt with patients' awareness and awareness skills but not on the classic psychoanalytic dependence on the analyst's interpretation of the unconscious. What is more, in Gestalt therapy, the therapist is actively and personally engaged with the patient, in the interim, the classic psychoanalysis, and the psychoanalyst remains neutral.

The Gestalt specialist uses active methods that develop not only learners' awareness but also their repertoires 
of awareness and behavioral instruments. The active methods and active personal engagement of Gestalt psychology are used to raise learners' awareness, freedom, and self-direction in a secure surrounding. Moreover, the biggest advantage of Gestalt psychology to learning theory was the accent on perception and reintegration of relationships within an organized whole. Based on Confluent language learning approach, methodological activities of the research were supposed to bond the three basic elements of learning: cognitive, affective, and psychomotor so as to combine feelings and perception into one holistic learning experience.

The key to Confluent second learning and acquisition approach lies on the interactive process that takes place between the cognitive and affective fields through any provided learning experience; this interactive process becomes the "gestalt" of the learning experience. The influence of Gestalt psychology on Confluent approach is the realization of the idea of a totally emotionally and intellectually integrated person. Therefore, the purpose of the selected methods is to sustain security and freedom in the classroom, to help to facilitate and simplify the control of the learning process. Of course, the teachers have to follow the procedural controls invoking the schemata: student-centered with freewheeling, free conversation, free discussion, and free expression.

Thus, Gestalt therapy foundation was construed and implemented into the Confluent second foreign language learning and acquisition approach with its Humanistic attitude to carry out the experiment with the subject of the research: the cadets of the MAL. The experiment proceeded in unison with holistic language learning and acquisition methodologies. The object of the research was realized on Confluent second language learning and acquisition approach by implementing: self-reflection, interpersonal dialogue and skills mastery via (1) here and now teaching, (2) student output as class content for language practice, (3) interpersonal sharing and (4) self-awareness methods.

Hence, the confluence approach stimulates holistic learning, involving body, mind, emotion and spirit. As a result, Confluent second language learning and acquisition approach is supposed to be based on the learner's interests bouncing to self-learning, interpersonal sharing and dialogue, and self-awareness. The learners learn multi-dimensionally about themselves and others at the same time they learn the traditional structures of the language.

While formulating the holistic learning construction on the subject of the research (cadets), we also relied on J. Heron's (1996) original formulation of the holistic learning model in which he describes learning as an interaction between four distinct modes of psychological being: feeling, imagining, thinking and practicing. Through the spectrum of Confluent learning approach, Confluent language learning and acquisition is viewed primarily as a means for affective reflective communication. Consequently, Confluent language learning and acquisition approach methods are supposed to be effectively incorporated into already existing curriculum, syllabus, materials or simply methods with the purpose to serve expanding and enhancing traditional materials. The objective of Confluent language learning and acquisition methods was to integrate them effectively into interpersonal learning language process by sustaining secure second learning and acquisition ambience.

In addition, while formulating the holistic learning construction on the subject of the research (cadets), we considered the importance of implementing Suggestopedia or Desuggestopedia, the so-called "humanistic approaches" into experimental group for we needed the notion of positive suggestion which could make the learner more receptive and, in turn, stimulate second language learning and acquisition. In addition, this method of holistic approach an easily integrate and stimulate such elements as cognitive and affective capabilities able to put the learner in certain conditions known as to accelerated teaching.

G. Lozanov (1976) stated that the ability to learn diminishes if a student feels stress related to fear of making a mistake or any other failure. G. Lazanov (1976) was engaged in experimental research on emotion and feeling influence on language teaching and learning for many years. As a result, he developed the approach which was based on the power of suggestion in learning, the notion of positive suggestion which makes the learner more receptive and, in turn, stimulates the learning. In addition, the emotions are essential to success of the human learning process in corpora with a well scrutinized idea validated by cognitive science. This 
learning method successfully blocks: fear, guilt, complexes and releases natural individual learning abilities. Curriculum comprehension and memory storage is ultimate in a physically and mentally relaxing atmosphere. In our research, we applied Suggestopedic classroom ambience necessary to reduce competition and stresses cooperation. Hence, cadets were not disillusioned with difficult tasks and verbal confidence for they were constantly reinforced by the teacher and his/her own progress awareness; even indifferent cadets tended to find themselves participating and enjoying language learning process. Based on the Suggestopedic classroom atmosphere, the individual feels safe to try out and make mistakes under the teacher's guidance. Moreover, G. Lozanov states that the negative thoughts that the learner has about herself or himself in learning has to be "de-suggested" (1976). Alias, Lozanov considers learning as a "global event" involving the whole person (Stevick 1976) and thinks that the learner is "constantly responding to innumerable influences, a few of which are conscious and rational, but most of which are either nonconscious or nonconscious or both" (ibid.).

\section{The results of Confluent second language learning and acquisition approach implementation in sustained secure ambience}

The purpose of the research was to construct such a Confluent second language learning and acquisition approach so as to imbalance perception and emotions in sustained secure ambience. In our research, Confluent second language learning and acquisition approach with its humanistic attitude was supposed to combine the cognitive and affective processes into one effective Confluent learning and acquisition experience. The effect of this approach was scrutinized primarily as a source for affective reflective communication on the basis of personal and individual experience merging with language proficiency in the classroom. Moreover, the experimental lessons were designed and organized in a way to obtain the research goals and objectives grounded on the results of the piloting projects that were constructed by the MAL teachers of foreign (Russian, English, German and French) languages. The experimental group was organized so that it comprised the methods of Confluent second language learning and acquisition approach. Moreover, Confluent second language learning and acquisition approach was incorporated into already existing syllabus, materials and served to expand traditional materials and methods so as to balance affective and interpersonal learning of an individual. In terms of research methodology, G. Lozanov's (1979) language learning and acquisition methods and principles were applied to experimental lessons: physical and psychical relaxation; specific learning suggestion, rhythmical breathing, changing way of speaking; repetition of material and its practical consolidation (writing, speaking, and reading in a second language). Therefore, they were integrated into the learning process, hence to intensify the affective filter, emotional freedom, relaxation and other affective features necessary to meet the research objectives and goals. Almost all the presented factors were supposed to proceed in 24-days involving nine thematic lesson plans based on the Lozanov (1979) method instructions. All the research days the learners proceeded listening to Baroque (Vivaldi's "Four Seasons") music in order to obtain as free as possible atmosphere of the classroom. Moreover, the chairs were organized in a semi-circle. Therefore, the lessons were being spent in holistic processing of the material when the learners spoke only then when the teacher requested in a group but seldom individually. In order to avoid tension and intimidation, the learners were taught to learn the language entirely orally for the first 3 days. The learning material was designed in a way to avoid stressful or uncomfortable situations. The following lessons were based on reinforcing and activating the previous lessons' material (based on typical teaching program), moving from holistic processing to mixed processing and then to the final highly analytic and cognitive including lexical and grammatical reinforcement, articulator exercises and singing.

During the experiment, the Confluent approach was used to "hammer", for example, a story read (or sung by some) out loud by the teacher or cadet and etc. Later, the research showed that this method better worked when a cadet distributed the text into the number of learners by asking them to read individually. According to the instruction a cadet had a command to concentrate on understanding the story but not on "learning" new vocabulary, grammar etc. An important principle, applied to this exercise (and all effective/affective materials), was to repeat exposure to a new material. Music was also played in the background as a means of stimulating the right brain participation. 
Webb (1990) states "certain types of musical rhythm help relax the body, calm the breath, quiet the beta chatter and evoke a gentle state of relaxed awareness which is highly receptive to learning new information". The Music Agent is able to deploy musical pieces specifically designed to enhance learning and retention.

The Confluent second language learning and acquisition approach at the MAL was applied likewise because of the idea that effective learning is suggestive in nature, not direct. In other words, learning and acquisition takes place through a combination of different types of right and left brain functions. During this process the longterm memory is semi-conscious so the teacher was to help to sidetrack the cadets with other things in order to allow them to receive information through peripheral perception.

Based on Confluent second language learning and acquisition approach, the research was organized in 2017 with to test the effectiveness of Confluent approach in accelerated language learning and acquisition. $553^{\mathrm{d}}$ year cadets of the Military Academy of Lithuania participated in the research. They were distributed into two groups, control (22 learners) and experimental (23 learners). The experimental group was taught according to Confluent, holistic approach; the control group studied in accordance to traditional teaching methodology without Confluent second language learning and acquisition approach. The obtained results were evaluated in accordance to a ten point system, where 10 points equal $100 \%$.

Table 1. Confluent approach

\begin{tabular}{|c|c|c|}
\hline Groups & Knowledge at the beginning of the course & Knowledge after the course \\
\hline Control & 5,7 & 6,9 \\
\hline Experimental & 5,9 & 8,3 \\
\hline
\end{tabular}

Source: created by authors

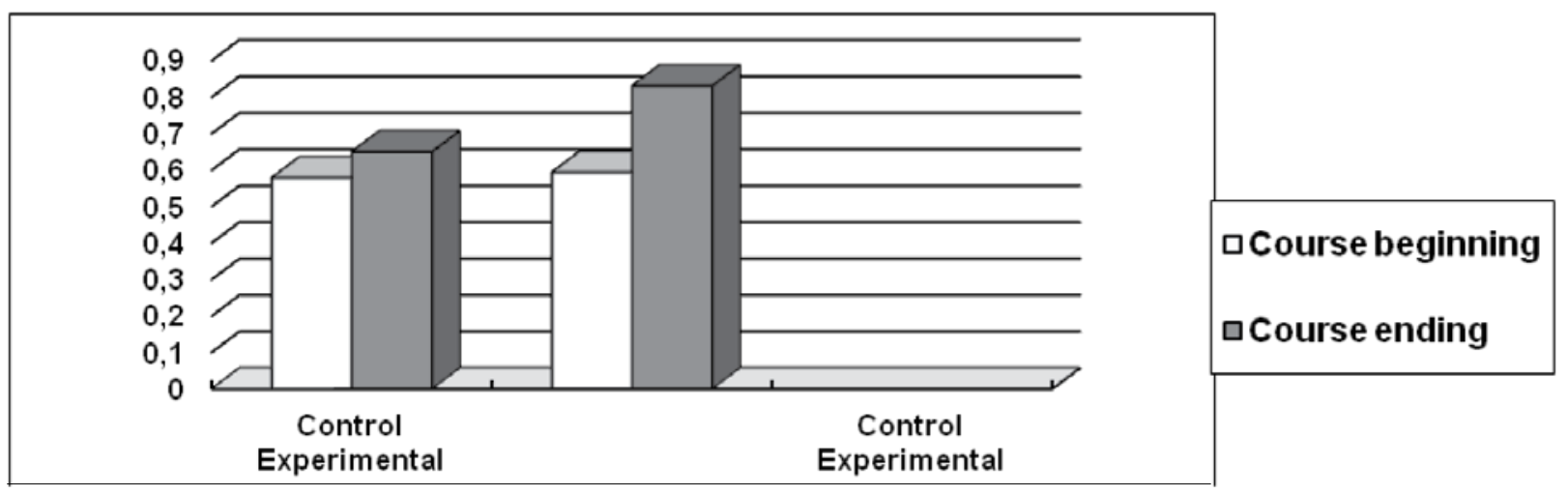

Fig. 1. Graphical exposure of the Confluent second language learning and acquisition approach implementation

Source: created by authors

In the research the obtained results demonstrated that during the Confluent language teaching cadets practiced structures that enabled them to reflect their own needs, wants, concerns, interests, values, activities, and behaviors which they shared with each other and very interactively. The table and the graphic display the average increase of the second foreign language learning and acquisition under the influence of the implementation of the Confluent second language learning and acquisition approach in the research group. Meanwhile, the control group's knowledge did not exceed (7). 2 points were left to be acquired. This result shows that the Confluent second language learning and acquisition approach increases and magnifies the learners' memory retention, retrieval and recall. Therefore, positive results were obtained under the influence of Confluent second language learning and acquisition approach which lead to four main factors:

(1) The language practice immersed in the "here and now" reality of class interaction.

(2) The linguistic content of the language, offered to cadets, was both cognitive (ideas, thoughts, facts and etc.) 
and affective (feelings, personal images, values, interests and etc.).

(3) Close relationships established among class members.

(4) Self-reflection and self-disclosure were encouraged as a means to self - knowledge.

In addition, during the experiment with the integrated Confluent second language learning and acquisition approach groups, the cadets were forced to explore and discuss various aspects about themselves in the target language. For example, they were focused on naturally motivating "meaning nodes" (needs, concerns, interests, personality traits, values, attitudes, behaviors, dreams, personal imagery, and plans for the future). The target language served them as a means to attain self-awareness, self-expression, and self-affirmation necessary to stimulate and accelerate the second language learning and acquisition. Personal information, shared with the others during conversation and structure practice, leads to the subsequent ambience of warmth and openness. This secure and relaxed atmosphere stimulated cadets become bosom to themselves and to their teacher.

Recapitulating, it is necessary to endorse that some certain elements of the approach cannot be broadly realized and incorporated into conventional ambience of second foreign language learning and acquisition today. For instance, in the military teaching grounds, it is quite inadequate to exhibit such factors as décor, lighting and furniture with cushions and other relaxing attributes. But the use of music both in the background and as an accompaniment to certain activities can be easily implemented as a motivating and relaxing factor. Dialogues too have their uses. Albeit, perhaps the most significant idea, creating conditions in which learners are alert and receptive, is that it has a positive effect on intrinsic motivation. It does not matter if these conditions are best created by the use of classical music and the reading of dialogues, but there is no doubt that Confluent second language learning and acquisition approach has raised interesting questions in the areas of both learning and acquisition of the second foreign language.

\section{Conclusions}

Emotions are essential to the success of the human learning process and they establish the idea substantiated by cognitive science.

Confluent second language learning and acquisition approach helps to create an emotion-based and secure ambience integrating all of the key elements emanating from accelerated learning techniques providing the learners with the best possible and secure learning environments.

Emotional competence is the key to helping language learners acquire the skills, attitudes, values, and experiences that motivate constructive behaviours, make responsible and thoughtful decisions leading to positive and accelerating learning.

Confluent second language learning and acquisition approach fastens and stimulates freewheeling, free conversation, free discussion, and free expression. A variety of effectively designed four cognitive factors provided in the research group accelerated the second language learning and acquisition.

An understanding of language anxiety threshold will help learners and teachers to be aware of comfort and safety level of students, so as to avoid harmful feelings of anxiety and carry out interventions (e.g., coping strategies, tailored programs) whenever necessary to maximize and accelerate the learning.

The theory and findings applied in the research suggest that the capacity to experience positive emotions may be a fundamental human strength central in successful second foreign language learning. 


\section{References:}

Brown, G. I. (1971). Human teaching for human learning: An introduction to Confluent education. New York: Viking.

Černevičiūtė, J., Strazdas, R. (2018). Teamwork management in Creative industries: factors influencing productivity, Entrepreneurship and Sustainability Issues 6(2): 503-516. http://doi.org/10.9770/jesi.2018.6.2(3)

Damasio AR, Damasio H. (1994). Cortical systems for retrieval of concrete knowledge: the convergence zone framework. In: Large scale neuronal theories of the brain (Koch C, ed.), Cambridge, MA: MIT Press.

Dewey, J. (1938). Experience and Education. New York: Macmillan Company.

Dubauskas, G. (2016). The management of public finance literacy for sustainable economic environment, Journal of Security and Sustainability Issues 5(3): 403-409. https://doi.org/10.9770/jssi.2016.5.3(8)

Dzemyda, I.; Zacharevič, G.; Nedelko, Z. (2015). Sustainability of international business through trade specialists' education, Journal of Security and Sustainability Issues 4(3): 564-574. https://doi.org/10.9770/jssi.2015.4.3(6)S

Heron, J. (1996). Helping whole people learn. In D. Boud \& N. Miller, (eds) Working with experience: Animated learning, London: Routledge.

Hurbišová, P.; Davidová, M. (2016). Onwards enhanced security: education and development of military commanders within the Lithuanian and Austrian Armed Forces, Journal of Security and Sustainability Issues 5(3): 311-322. https://doi.org/10.9770/ jssi.2016.5.3(1)

Isen, A. M. (1990). The Influence of Positive and Negative Affect on Cognitive Organization: Some Implications for Development. In: Stein, N., Leventhal, B. and Trabasso, T., Eds., Psychological and Biological Approaches to Emotion, Hillsdale, Erlbaum, New Jersey.

Jensen E. (1998). Teaching with the brain in mind. Alexandria, VA: Association of Supervision and Curriculum Development.

Krashen, S. (1983). From the classroom to the real world: Solving the transition problem. Second Language Bulletin (Canadian Association of Second Language Teachers). September, 1983.

Krashen, S. (1983). Newmark's "ignorance hypothesis" and current second language acquisition theory. In S. Gass and L. Selinker (Eds.) Language Transfer in Language Learning. New York: Newbury House.

Krashen, S. (1983). The din in the head, input, and the language acquisition device. Foreign Language Annals 16: 41-44.

Krashen, S. (1983). The relationship between theory and practice. In R. Blair (Ed.) Innovative Approaches to Language Teaching and Language Learning. New York: Newbury House. pp. 15-30. Consciousness in second language learning. Acquisition theory' in S. Gass and L. Selinker (eds.): Language Transfer in Language Learning. Rowley, Mass.: Newbury House.

Labanauskis, R.; Kasparavičiūtè, A.; Davidavičienè, V.; Deltuvienė D. (2018). Towards Quality Assurance of the Study Process Using the Multi-Criteria Decision-Making Method, Entrepreneurship and Sustainability Issues 6(2): 799-819. http://doi.org/10.9770/ jesi.2018.6.2(22)

Le Doux, J. (1996). The Emotional Brain: The Mysterious Underpinnings of Emotional Life. New York: Simon and Schuster.

Lincaru, C., Pirciog, S., Grigorescu, A., Tudose, G. (2018). Low-Low (LL) High Human Capital Clusters In Public Administration Employment - Predictor for Digital Infrastructure Public Investment Priority - Romania Case Study, Entrepreneurship and Sustainability Issues 6(2): 729-753. http://doi.org/10.9770/jesi.2018.6.2(18)

Lozanov, G. (1978). Suggestology and Suggestopedia: Theory and Practice: (Working document), Sophia, Bulgaria: United National Educational Scientific and Cultural Organization.

Lozanov, G. (1978). The Suggestological theory of communication and instruction. The Journal of the Society for Accelerative Learning and Teaching, 3 (1).

Lozanov, G. (1979). Suggestology and Outlines of Suggestopedia. New York, Gordon, and Breach Pub.

Mačiulis, A.; Tvaronavičienė, M. (2013). Secure and sustainable development: Lithuania's new role in taking the Presidency of the EU, Journal of Security and Sustainability Issues 3(2): 5-13. https://doi.org/10.9770/jssi.2013.3.2(1)

Misch, D. A., Peloquin, S. M. (2005). Developing empathy through Confluent education. Journal of Physical Therapy Education, 19 (3) 
Perls, F. S. (1969a). Ego, Hunger, and Aggression. New York: Random House.

Perls, F. S. (1970). Four lectures. In: Gestalt Therapy Now: Theory, Techniques, and Applications, J. Fagan and I. L. Shepherd (eds.). New York: Harper Colophon Books, pp. 14-38.

Perls, F. S. (1976). The Gestalt Approach and Eye Witness to Therapy. New York: Bantam Books.

Perls, F. S. (1992). Gestalt Therapy Verbatim. Highland, NY: Gestalt Journal Press.

Perls, F., Hefferline, R. F., Goodman, P. (1951). Gestalt therapy: Excitement and growth in the human personality. New York: Gestalt Journal Press.

Radović-Marković, M. (2011). Critical employment analysis: theory, methodology and research, Journal of Security and Sustainability Issues 1(2): 113-121. https://doi.org/10.9770/jssi.2011.1.2(4)

Saleem, F., Adeel, A., Rizwan Ali, Hyder, S. (2018). Intentions to adopt ecopreneurship: moderating role of collectivism and altruism, Entrepreneurship and Sustainability Issues 6(2): 517-537. http://doi.org/10.9770/jesi.2018.6.2(4)

Schumann, J. (1994). Where is cognition? Emotion and cognition in second language acquisition. Studies in Second Language Acquisition, 16.

Sellers, V. (2000). Anxiety and reading comprehension in Spanish as a foreign language. Foreign Language Annals, 33.

Smith, M. K. (2001). Lifelong Learning, the Encyclopaedias of Informal Education. Available on Internet: http://www.infed.org/ lifelonglearning/

Stevick, E. (1976). Memory, Meaning, and Method. Rowley, Ma.: Newbury House.

Stevick, E. (1980). Teaching Languages: A Way and Ways. Rowley, Ma.: Newbury House.

Thompson, M. (2011) http://nation.time.com/author/mt53/page/128/?order=DESC

Wagner-Moore, L. E. (2004). Gestalt Therapy: Past, Present, Theory, and Research. Psychotherapy: Theory, Research, Practice, Training, 41(2). Available on Internet: http://dx.doi.org/10.1037/0033-3204.41.2.180

Williams, M., Burden, R. (1997) Psychology for Language Teachers: a Social Constructivist Approach. Cambridge University Press, Cambridge.

Worde, R. (1998). An investigation of students' perspectives on foreign language anxiety. Unpublished doctoral dissertation, George Mason University, Fairfax, Virginia.

\author{
About contributors: \\ Dileta JATAUTAITE, Ph. D. Assoc. Prof. The Department of Humanities at the General Jonas Žemaitis Military Academy of Lithuania. \\ Field of interests: language teaching and learning methodology, traditional and nontraditional language learning, language psychology, \\ memory, emotions, motivation and etc. \\ ORCID ID: https://orcid.org/0000-0003-4753-618X
}

Jelena KAZIMIANEC, Ph.D. Assoc. Prof. The Department of Humanities at the General Jonas Žemaitis Military Academy of Lithuania. Field of interests: language teaching and learning methodology, Comparative linguistics, socio linguistics ORCID ID: https://orcid.org/0000-0003-2639-7993 